\title{
INTRAVENOUS GLUCOSE TOLERANCE TEST DURING ANAESTHESIA IN DOGS: INSULIN RESPONSE AND GLUCOSE CLEARANCE
}

\author{
Hironori Ishihara, Frank T. Kallus and A.H. Giesecke, Jr
}

\begin{abstract}
To evaluate the insulin response and the rates of disappearance of glucose from plasma during high spinal analgesia and various types of general anaesthesia, a series of intravenous glucose tolerance tests was performed in six dogs. Plasma glucose and insulin levels were measured during the intravenous glucose tolerance tests. Insulinogenic indices were calculated. The values obtained during anaesthesia were compared to those obtained during an unanaesthetized state. The insulinogenic index was increased significantly during high spinal analgesia and thiopentone infusion. Halothane and enflurane anaesthesia decreased the insulinogenic index significantly while Innovar ${ }^{\text {id }}$-nitrous oxide also decreased it, but not significantly. These findings suggest that insulin secretion in response to hyperglycaemia is stimulated by spinal analgesia and thiopentone anaesthesia, depressed by halothane and enflurane anaesthesia and unchanged during neuroleptanacsthesia.

A diuresis was observed in the thiopentone anaesthetic and spinal analgesic groups as compared to the other general anaesthetic groups. Urinary losses of insulin and glucose paralleled urinary output; yet the greatest mean urinary loss of glucose did not exceed $4.5 \mathrm{per}$ cent of the load of glucose administered. Accordingly, 95 per cent of the administered glucose remained within the body, presumably available for utilization.
\end{abstract}

KEY WORDs: Glucose, insulin, anaesthetics, insulinogenic index.

THE OBSERVATION of spontaneous hyperglycaemia under the influence of diethyl ether anaesthesia has led to speculation regarding the effects of anaesthesia on insulin release. Plasma insulin levels are elevated as compared to fasting control levels during diethyl ether anaesthesia. ${ }^{1}$ In contrast, plasma insulin levels are unchanged under the influence of halothane,,$^{2,3}$ methoxyflurane, ${ }^{3,4}$ enflurane, ${ }^{5}$ or spinal analgesia ${ }^{6}$ and have been reported to be significantly decreased during epidural analgesia.? All of these reports were of data collected in studies which did not include a glucose challenge. Insulin secretion is known to be controlled by substrates, the autonomic nervous system and various hormones. Exogenous hyperglycaemia is the most important physiological stimulus for insulin release in normal unmanipulated mammals. Under various types of exogenous glucose challenges, serum insulin

Hironori Ishihara, M.D., Research Fellow in Anesthesiology on leave of absence from the Department of Anesthesiology, Hirosaki University School of Medicine, Hirosaki Amori-Ken, Japan; Frank T. Kallus, M.D., Ph.D., Assistant Professor of Anesthesiology; A.H. Giesecke, Jr., M.D., Jenkins Professor and Vice Chairman; Department of Anesthesiology, University of Texas Southwestern Medical School, 5323 Harry Hines Blyd., Dallas, Texas 75235

Reprint requests to Dr. Kallus.

Canad. Anaesth. Soc. J., vol. 28, no. 4, July 1981 responses were reported to be unchanged by thiopentone-nitrous oxide ${ }^{8}$ and cyclopropane anaesthesia, ${ }^{9}$ and suppressed by halothane and methoxyflurane anaesthesia. ${ }^{3}$ Epidural analgesia has been reported to increase the insulin response to a glucose load. ${ }^{10}$ In isolated islets, both inhalational ${ }^{11.12}$ and local anaesthetics ${ }^{13.14}$ have also been found to inhibit glucosc-stimulated insulin secretion.

The present study reports the insulin response to an intravenous glucose load in dogs during an unanaesthetized control state and during high spinal analgesia or general anaesthesia with halothane, enflurane, Innovar ${ }^{\circledR}$-nitrous oxide or thiopentone-oxygen.

\section{Materials AND Methods}

\section{General}

Six mongrel dogs of either sex weighing 11.5 to $19.5 \mathrm{~kg}$ were fed standard commercial dry dog food for at least two weeks before the experiment and were conditioned to sit quietly in the laboratory during intravenous infusions and drawing of blood samples. The animals were fasted for 18-22 hours before each experiment. An intravenous catheter (Angiocath 18 gauge) was inserted percutaneously into a cephalic vein and 
connected to a heparin lock after a preinduction blood sample was drawn.

A glucose 50 per cent solution $\left(0.5 \mathrm{~g} \cdot \mathrm{kg}^{-1}\right.$ body wt) was infused for three minutes to initiate the intravenous glucose tolerance test. Blood and urine samples were taken periodically and fluid was administered according to the scheme shown in Figure 1. Each dog was the subject of an unanaesthetized control intravenous glucose tolerance test and five additional similar tests done after a stable state of anaesthesia was achieved. They were repeated serially during randomly selected anaesthetics. A minimum interval of a week was allowed between each anaesthetic and intravenous glucose tolerance test on each dog.

All anaesthetics were induced with intravenous thiopentone $30 \mathrm{mg} \cdot \mathrm{kg}^{-1}$. No premedication was used. The trachea was intubated and the lungs were ventilated mechanically with a Harvard small animal respirator. Ventilation was adjusted to maintain $\mathrm{Pa}_{\mathrm{CO}_{2}}$ between 4.67 and $5.34 \mathrm{kPa}$ (35 and 40 Torr) as indicated by arterial blood gas analysis. Lactated Ringer's solution was infused continuously at the rate of $10 \mathrm{ml} \cdot \mathrm{kg}^{-1} \cdot \mathrm{hr}^{-1}$ from the induction of anaesthesia throughout the entire experiment. Oesophageal temperature was monitored during anaesthesia, and the temperature was maintained between $37.5^{\circ}-40.1^{\circ} \mathrm{C}$ with a heating pad. A sterile urethral catheter was placed into the bladder after the induction of anaesthesia in three male dogs and urine was collected for sixty minutes durng the intravenous glucose tolerance test to measure urinary loss of insulin and glucose.

\section{Spinal Analgesia}

After tracheal intubation, lumbar puncture was done using a method similar to that described by Redderson, et al. ${ }^{15}$ Tetracaine 1 per cent $(1.5 \mathrm{ml})$ was mixed with dextrose 10 per cent $(2.5 \mathrm{ml})$ for the block. Incremental doses of thiopentone

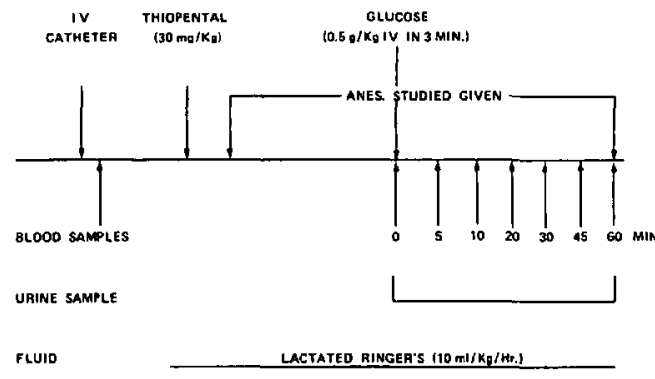

Figure 1 Protocol of the study.
$40 \mathrm{mg}$ were injected as required to keep the dog anaesthetized during the lumbar puncture. After a stable state of spinal analgesia had been obtained, the animal was allowed to breathe spontaneously and the trachea was extubated. The effectiveness of the block was confirmed by observing loss of spontaneous motor activity, absence of withdrawal to painful stimuli and abdominal breathing. All blocks were above T1 and below $\mathrm{C} 5$. The experimental intravenous glucose tolerance tests were done $69 \pm 4$ minutes after the tetracaine injection.

\section{General Anaesthesia}

The anaesthetic agents included in the present study were (1) halothane 1.7 per cent in oxygen, (2) influrane 4.4 per cent in oxygen, (3) thiopentone $8-16 \mathrm{mg} \cdot \mathrm{kg}^{-1} \cdot \mathrm{hr}^{-1}$ by intravenous infusion as deemed necessary for the maintenance of an immobile state and (4) Innovar ${ }^{(\$)}$-vet $0.3 \mathrm{ml}$ (droperidol $6 \mathrm{mg}$ plus fentanyl $0.12 \mathrm{mg}$ ) was given intravenously over five minutes and followed by an infusion of the drug at the rate of $0.3 \mathrm{ml} \cdot \mathrm{hr}^{-1}$. A stable state was achieved $49 \pm 1$ minutes after the induction of general anaesthesia.

\section{Analyses and Calculations}

The blood samples were collected into chilled tubes and plasma was separated immediately and stored at minus $20^{\circ} \mathrm{C}$ for subsequent analysis in batches. Plasma and urinary insulin was measured using an insulin radioimmunoassay kit (Amersham). Urine $\mathrm{pH}$ was adjusted to $7.0-8.0$ before assay.

Immunoreactive insulin concentrations were calculated using the least squares regression line of a logit/log plot of radioimmunoassay data. ${ }^{16}$

Plasma and urine glucose were determined by the o-toluidine method. ${ }^{17}$ All analyses were done in duplicate and averaged.

The insulinogenic index, as described by Seltzer, et al. ${ }^{18}$ was calculated as the area above basal described by the plasma immunoreactive insulin curve (i.e., the increment above fasting level) divided by the area above basal of the plasma glucose curve for the timed samples $(\Delta \mathrm{I} / \Delta \mathrm{G})$.

Statistical evaluation of the three curves (insulinogenic index vs time, plasma immunoreactive insulin vs time, and plasma glucose vs time) was accomplished by use of a repeated measures analysis of variance test. This was followed by use of the Newman-Keuls multiple comparison procedure $^{19}$ for which the significance level was set at 0.05 . 


\section{RESULTS}

\section{Plasma Glucose}

No statistically significant difference was ob. served between the preinduction glucose concentration and the level at time zero (Figure 2) in spite of the fact that considerable time under anaesthesia had elapsed between the two samples in both the spinal analgesia and the general anaesthetic groups. Five minutes after the intravenous glucose load was given, blood sugar levels increased to a mean value of $297 \mathrm{mg}$ per cent (range 217-660) for all animals; certainly an adequate stimulus for insulin release. From 20 to 60 minutes the glucose decay curves fell into two significantly different groups, with halothane, enflurane and neuroleptanaesthesia following a delayed type of disappearance pattern compared to control, thiopentone and spinal analgesia.

\section{Plasma Immunoreactive Insulin}

Basal plasma immunoreactive insulin was not significantly different from control in all groups (Figure 3). However, plasma immunoreactive insulin levels during thiopentone anaesthesia and spinal analgesia were significantly greater ( $p=$ 0.05 ) than that of control at 5, 10 and 20 minutes. No statistically significant difference was seen with the other general anaesthetics with the single exception of the halothane group, which was lower $(\mathrm{p}=0.05)$ than control at 10 minutes.

\section{Insulinogenic Index}

The insulinogenic indices (Figure 4) tended to fall into three groups. Thiopentone anaesthesia and spinal analgesia groups had significantly higher $(p=0.05)$ insulinogenic indices than the unanaesthetized control group throughout the intravenous glucose tolerance test. The insulin-

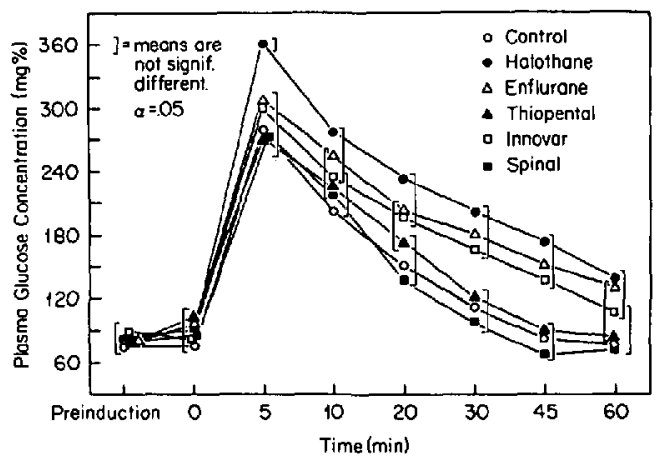

Figure 2 Mean plasma glucose concentrations versus time. The intravenous glucose tolerance test was begun at time zero, $n=6$.

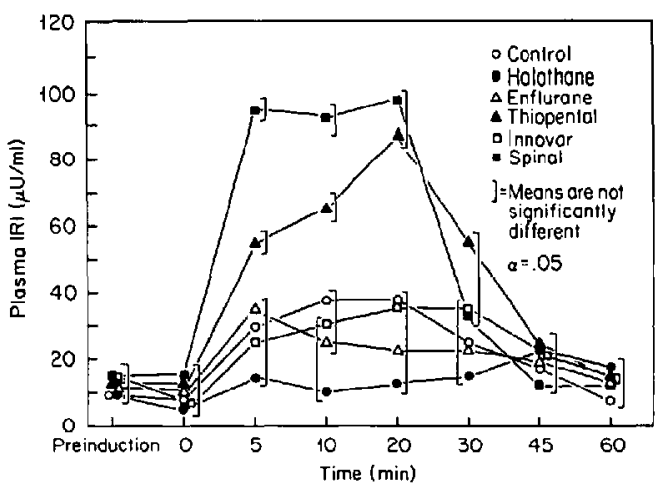

FIgURE 3 Mean plasma immunoreactive insulin concentrations versus time. The intravenous glucose tolerance test was begun at time zero. $n=6$.

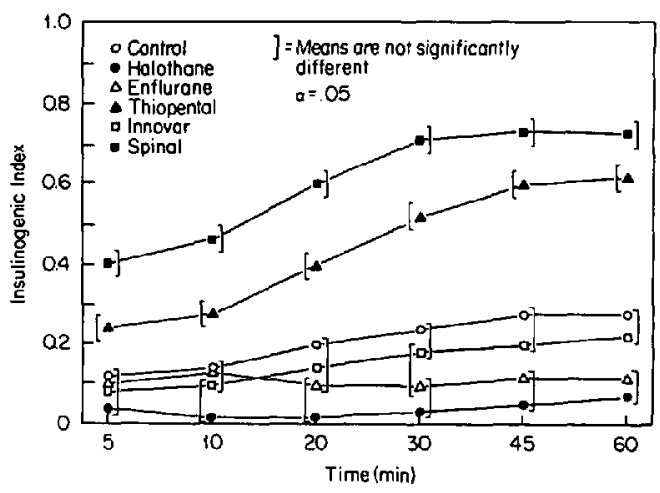

FIGURE 4 Insulinogenic indices versus time. The intravenous glucose tolerance test was begun at time zero. $n=6$

ogenic indices of the halothane and enflurane groups were significantly lower $(\mathrm{p}=0.05)$ than control after 20 minutes and the neuroleptanaesthesia group was not different from control.

\section{Urinary Losses}

Urinary losses of glucose and insulin and urinary volumes are shown in Table I. These data were obtained during the five anaesthetics from three male dogs. A diuresis occurred in the thiopentone and spinal groups. Urinary insulin and glucose excretion paralleled urinary output. However, the mean glucose loss did not exceed 4.5 per cent of the glucose load. Plasma glucose concentration fell below renal threshold within 45 minutes.

\section{Discussion}

Our data agree with reports showing that during various types of anaesthesia without a 
TABLE 1

URINARY LOSSES

\begin{tabular}{lccccc}
\hline & Halothane & Enflurane & Thiopent & Innovar & Spinal \\
\hline Glucose* & $0.33 \pm 0.23 \dagger$ & $0.40 \pm 0.40$ & $1.85 \pm 0.73$ & $0.84 \pm 0.31$ & $4.50 \pm 1.57$ \\
Insulin $\ddagger$ & $167 \pm 90$ & $121 \pm 121$ & $3156 \pm 2321$ & $338 \pm 130$ & $6605 \pm 1314$ \\
Volume§ & $6.0 \pm 3.8$ & $6.8 \pm 6.8$ & $122.1 \pm 33.9$ & $20.1 \pm 8.1$ & $127.2 \pm 16.1$ \\
\hline
\end{tabular}

* Percent of intravenous glucose tolerance test $/ 60 \mathrm{~min}$.

†Mean \pm SE.

$\ddagger \mu \mathrm{U} / 60 \mathrm{~min}$.

$\$ \mathrm{ml} / 60 \mathrm{~min}$.

glycaemic stimulus, plasma immunoreactive insulin levels do not change significantly. ${ }^{1-6,8}$

Since glucose administration is frequently a part of operative fluid management, it is important to study the effects of anaesthesia on the glucose-insulin response. Using the insulinogenic index and plasma immunoreactive insulin levels as indicators of the insulin response to exogenous glucose, our data show that high spinal analgesia and continuous thiopentone anaesthesia enhance the insulin response. Our study did not address mechanisms; however, high spinal analgesia resulting in removal of sympathetic inhibition ${ }^{20}$ of insulin release could cause an enhanced insulin response. The level of autonomic blockade is probably important in modifying the insulin response to a glucose challenge. On two occasions, the spinal block was high enough for the dogs to become apnoeic and to require artificial ventilation. The average 60 minute insulinogenic index for those two dogs was 0.21 , which is very similar to the mean of 0.28 for the control group. Since total autonomic blockade was probably achieved, both sympathetic inhibition and parasympathetic stimulation were abolished. The data from these two spinal blocks were excluded from the results because of the profound difference in the level of the block. Houghton, et al. ${ }^{10}$ also reported a stimulated insulin response to a glucose load under epidural analgesia which they explained on the basis of afferent and efferent blockade of sympathetic inhibition of the insulin response.

The augmented response observed during continuous thiopentone anaesthesia may also be due to effects on the autonomic influence of insulin release. Barbiturates decrease sympathetic activity ${ }^{21,22}$ and remove sympathetic inhibition of insulin release with the net result being an enhanced insulin response to a glucose challenge.

Induction with thiopentone was a common denominator in all of the anaesthetics. This was felt to be an appropriate and humane way to begin each experiment since Oyama, et al. ${ }^{8}$ had reported that thiopentone-nitrous oxide anaesthesia had no influence on plasma insulin concentrations. We included a group in which anaesthesia was maintained throughout the experiment with a thiopentone infusion to observe the effects of the drug under the conditions of our experiment and we were surprised to find an augmented insulin response to a glycaemic challenge. The insulinogenic index for the thiopentone group indicates significantly enhanced insulin release, whereas the other general anaesthetics were below control. Since the metabolic half-life of thiopentone greatly exceeds the hypnotic half-life of thiopentone one has to consider the possibility that without the thiopentone induction the other general anaesthetics might have exhibited an earlier or more profound depression of insulin response and the spinal analgesia group may have shown its stimulated insulin response later.

There is no obvious explanation for the difference in our observations and the report of Oyama, et al. ${ }^{8}$ regarding thiopentone effects on plasma immunoreactive insulin. However, in their study premedications were used which have known effects on the autonomic nervous system. Also, the glucose challenge was considerably different in magnitude and time course; approximately $0.14 \mathrm{~g} \cdot \mathrm{kg}^{-1}$ in $45 \mathrm{~min}$ versus 0.5 $\mathrm{g} \cdot \mathrm{kg}^{-1}$ in $3 \mathrm{~min}$. In their study the peak plasma glucose level reported was only $135 \mathrm{mg}$ per cent at 45 minutes whereas our lowest peak plasma glucose concentration was $217 \mathrm{mg}$ per cent in five minutes.

Considering the patterns of the plasma immunoreactive insulin and plasma glucose curves, one is not surprised to see the three general anaesthetic groups having a low insulin response also achieving the higher glucose levels and having a delayed disappearance pattern for glucose. On the other hand, one might expect that in the thiopentone anaesthetic and spinal analgesic 
groups, which had markedly elevated plasma immunoreactive insulin levels, that both of them would have shown glucose disappearance patterns much faster than the control group. However, that was not observed. One has to consider two prime possibilities to account for this dispari$\mathrm{t} y$; insulin antagonis $\mathrm{m}$ and increased endogenous glucose production. Oyama, et al..$^{6.23}$ report no change in levels of human growth hormone or of cortisol with either spinal or thiopentone anaesthesia, making insulin antagonism unlikely. Endogenous glucose release could occur through glycogenolysis stimulated by epinephrine or glucagon. Hamelberg ${ }^{24}$ reported that spinal analgesia does not stimulate epinephrine and thiopentone is said to decrease sympathetic activity. ${ }^{22,23}$ Likewise, gluconeogenesis due to cortisol or epinephrine effects seems unlikely. Unfortunately, we have no data and we found no relevant reports in the literature about the effects of anaesthetics on glucagon levels.

In the clinical circumstance, frequently $25 \mathrm{~g}$ of glucose is given during the first 15 to 30 minutes of andesthesia. This would approximate $0.36 \mathrm{~g} \cdot \mathrm{kg}^{-1}$ in $15-30 \mathrm{~min}$ in the "average" $70 \mathrm{~kg}$ person. We used $0.5 \mathrm{~g} \cdot \mathrm{kg}^{-1}$ in $3 \mathrm{~min}$ in our study and found the greatest mean urinary loss of glucose not to exceed five per cent of the glucose load administered. Regardless of the anaesthetics, 95 per cent of the glucose load remained within the animals until plasma glucose concentrations were well below renal threshold and presumably that glucose was available for utilization.

\section{REFERENCES}

1. Yoshimura, N., Kodama, K. \& Yoshitake, J. Carbohydrate metabolism and insulin release during ether and halothane anaesthesia. $\mathrm{Br}$. J. Anaesth. 43: 1022 (1971).

2. Oyama, T. \& TAkazawa, T, Effects of halothane anaesthesia and surgery on human growth hormone and insulin levels in plasma. $\mathrm{Br}$. J. Anaesth. 43: 573 (1971).

3. Merin, R.G., Samuelson, P.N. \& Schalch, D.S. Major inhalation anesthetics and carbohydrate metabolism. Anesth. Analg. 50:625 (1971).

4. Oyama, T. \& Takazawa, T. Effect of methoxyflurane anaesthesia and surgery on human growth hormone and insulin levels in plasma. Canad. Anaesth. Soc. J. 17: 347 (1970).

5. Oyama, T., Matsuki, A. \& Kudo, M. Effects of enflurane (Ethrane) anaesthesia and surgery on carbohydrate and fat metabolism in man. Anaesthesia 27: 179 (1972).

6. Oyama, T. \& Matsuki, A. Effects of spinal anaesthesia and surgery on carbohydrate and fat metabolism in man. Br. J. Anaesth. 42: 723 (1970).

7. Brandt, M.R., Kehlet, H., Faber, O. \& Bind-
ER, Chr. C.Peptide and insulin during blockage of the hyperglycemic response to surgery by epidural analgesia. Clin, Endocrinol. 6: 167 (1977).

8. Orama, T., Takiguchi, M. \& Kudo, T. Metabolic effects of anaesthesia: effect of thiopentonenitrous oxide anaesthesia on human growth hormone and insulin levels in plasma. Canad. Anaesth. Soc. J. 18; 442 (1971).

9. OYama, T. \& Takazawa. T. Effect of Cyclopropane anesthesia and surgery on carbohydrate and fat metabolism in man. Anesth. Analg. 51: 389 (1972).

10. Houghton, A., Hickey, J.B., Ross, S.A. \& Dupre, J. Glucose tolerance during anacsthesia and surgery. Comparison of general and extradural anaesthesia. Br. J. Anaesth. 50: 495 (1978).

11. Gingerich, R., Wright, P.H. \& Paradise, R.R. Inhibition by halothane of glucose-stimulated insulin secretion in isolated pieces of rat pancreas. Anesthesiology 40: 449 (1974).

12. Gingerich, R., Paradise, R.R. \& Wright, P.H. Inhibition by ether of glucose-stimulated insulin secretion in isolated pieces of rat pancreas. Anesthesiology 51: 34 (1979).

13. Brisson, G. R., Camu, F., Malaisse-Lagae, F., \& MALAISSE, W.J. Effect of a local anesthetic upon calcium uptake and insulin secretion by isolated islets of Langerhans. Life Sci. 10: 445 (1971).

14. TJalve, H., Popov, D. \& Slania, P. Effect of the local anesthetics procaine and lidocaine on insulin secretion from rabbit pancreas pieces. Horm Metab. Res. 6: 106 (1974).

15. Redderson, C.L., Uy, D. \& ANTon, A.H. New techniques for spinal anesthesia in the dog. Anesthesiology 40: 187 (1974).

16. Rodbard, D., Bridson, W. \& Rayford, P.L. Rapid calculation of radioimmunoassay results. J. Lab. Clin. Med. 74: 770 (1969).

17. Duвowski, K.M. An o-toluidine method for bodyfluid glucose determination. Clin. Chem. 8: 215 (1962).

18. Seltzer, H.S., Allen, E.W., Herron, Jr., A.L. \& BRENNAN, M.T. Insulin secretion in response to glycemic stimulus: relation of delayed initial release to carbohydrate intolerance in mild diabetes mellitus. J. Clin. Invest. 46: 323 (1967).

19. Winer, B.J. Statistical Principles in Experimental Design, 2nd ed. New York: McGraw-Hill (1971).

20. Porte, JR., D. \& Robertson, R.P. Control of insulin section by catecholamines, stress, and the sympathetic nervous system. Fed. Proc. 32: 1792 (1973).

21. Harvey, S.C. Hypnotics and Sedatives. In: Goodman, L.S. \& Gilman, A. The Pharmacological Basis of Therapeutics, 6th ed. New York: The Macmillan Company (1980)

22. Millar, R.A., Warden, J.C., Cooperman, L.H. \& PRICE, H.L. Further studies of sympathetic actions of anaesthetics in intact and spinal animals. Br. J. Anaesth. 42: 366 (1970).

23. Oyama, T., Takigucki, M., Aokı, N. \& Kudo, T. Adrenocortical function related to thiopentalnitrous oxide oxygen anesthesia and surgery in man. Anesth. Analg. 50: 727 (1971).

24. Hamelberg, W., Sprouse, J.H., Mahaffey, J.E. \& RichaRdSON, J.A. Catecholamine levels during light and deep anesthesia. Anesthesiology $21: 297$ (1960). 


\section{RÉSUMÉ}

Dans le but d'évaluer la réponse à l'insuline et la vitesse de disparition du glucose plasmatique pendant l'anesthésie rachidienne haute et pendant différents types d'anesthésies générales, des épreuves de tolérance au glucose intraveineux ont été effectuées sur six (6) chiens. Pendant l'épreuve de tolérance on a mesuré le glucose plasmatique et le niveau d'insuline. L'indice insulinogénique a été calculé. Le valeurs obtenues pendant les l'anesthésie ont été comparées à celles obtenues en l'absence d'anesthésie. L'indice insulinogénique a augmenté de façon significative lors de l'anesthésie rachidienne haute et pendant l'infusion de thiopentone. L'anesthésie à l'halothane et l'enflurane ont diminué de façon significative l'index insulinogénique alors que l'Innovar-protoxyde d'azote l'ont aussi diminué mais de façon non significative. Ces données portent à croire que la sécrétion d'insuline secondaire à l'hyperglycémie est stimulée par l'anesthésie rachidienne et l'anesthésie au thiopentone, déprimée par l'anesthésie à l'halothane et l'enflurane et inchangée pendant la neuroleptanesthésie.

On a observé une diurèse pendant l'anesthésie au thiopentone et l'anesthésie rachidienne en comparaison avec les autres groupes d'anesthésies générales. Les pertes urinaires d'insuline et de glucose étaient proportionnelles au débit urinaire; cependant la plus grande perte moyenne par l'urine de glucose n'a pas dépassé 4.5 pour cent de la charge de glucose administré; 95 pour cent du glucose administré est donc resté dans l'organisme et on peut présumer qu'il était disponible pour utilisation. 